\title{
Barriers to Condom Use Among Female Sex Workers in Tehran, Iran: A Qualitative Study
}

This article was published in the following Dove Press journal:

International Journal of Women's Health

Mohammad Ali Mohammadi

Gharehghani'

Bahar khosravi ${ }^{2}$

Seyed Fahim Irandoost (iD ${ }^{3}$

Goli Soofizad ${ }^{4}$

Javad Yoosefi lebni ${ }^{5}$

ISocial Welfare Management

Research Center, University of Social Welfare and Rehabilitation Sciences, Tehran, Iran; ${ }^{2}$ Students Research Committee, Kermanshah University of Medical Sciences, Kermanshah, Iran; ${ }^{3}$ Department of Public Health, School of Health, Urmia University of Medical Sciences, Urmia, Iran; ${ }^{4}$ School of Public Health and Safety, Shahid Beheshti University of Medical Sciences, Tehran, Iran; ${ }^{5}$ Health Education and Health Promotion, Health Promotion Research Center, Iran University of Medical Sciences, Tehran, Iran
Correspondence: Javad Yoosefi lebni Health Education and Health Promotion, Health Promotion Research Center, Iran University of Medical Sciences, Tehran, Iran

Email j.yousefi28@yahoo.com
Background: There are many barriers for condom use, which was one of the most important methods to prevent the transmission of HIV among female sex workers. Therefore, the aim of the present study was to identify the barriers to condom use among female sex workers in Tehran, Iran.

Methods: This study was conducted with a qualitative approach and conventional content analysis among female sex workers in Tehran. Twenty-two female sex workers were selected through snowball sampling and purposive sampling. The data gathering method was a semi-structured interview and the data were analyzed using Graneheim and Lundman method. Guba and Lincoln criteria were used for evaluating research transferability.

Results: The results of data analysis were categorized in three categories and seven sub-categories included 1) individual factors (not knowing HIV/AIDS properly, antiloyalty and love, and personality traits), 2) structural factors (partner's desire, problems with condom availability), and 3) cultural factors (cultural taboos, following the models).

Conclusion: The results showed that lack of condom use is the consequence of different individual, structural, and cultural factors. So, it can be useful to take some initiatives at the individual level by raising awareness and understanding of female sex workers about HIV at the structural level by lowering the price of condoms and providing them extensively and at the societal level, by changing the beliefs and taboos about condoms.

Keywords: female sex workers, condoms, barriers, qualitative study, Iran

\section{Introduction}

HIV is one of the most critical health issues in developing countries worldwide, killing thousands every year. ${ }^{1}$ HIV has been on the rise in Iran in recent years ${ }^{2}$ and its transition type has changed from injecting drug addiction to sexual relationships and this has become a significant concern in this country. ${ }^{3}$ One of the most important reasons for the transmission of HIV is having unprotected sex. ${ }^{4,5}$ Female sex workers are among the most vulnerable and high-risk groups for HIV due to their particular circumstances, ${ }^{6-8}$ with $15 \%$ of HIV cases attributed to unprotected sex work in adult women worldwide. Of course, if we consider the prevalence of HIV in other population groups affected by sex with female sex workers, the overall burden attributed to this high-risk behavior is much higher. ${ }^{9}$ Also, the probability of women getting HIV is 13 times that of all women of childbearing age in low- and middle-income countries. ${ }^{10}$ One of the essential reasons that female sex workers are exposed to HIV is having multiple sex partners and more importantly having an unprotected relationship. ${ }^{11}$ 
One of the most important ways to prevent the transmission of HIV in sexual relationships is the use of condoms. ${ }^{12-15}$ However, there is much resistance to not using it, ${ }^{16}$ with a prevalence of $0.42 \%$ reported among female sex workers. ${ }^{4}$ Lack of condom use is affected by various personal, social, environmental, and cultural factors. ${ }^{17-19}$

A qualitative study conducted by Januraga et al, 2020 in Bali, Malaysia, among 35 female sex workers showed that the two main reasons the prioritizing of financial stability and romantic relationships caused the not using condoms by female sex workers. However, the main reason for using condoms was to protect their health in order to improve their economic situation in the future. ${ }^{20}$ Iakunchykova \& Burlaka, 2020, in a study of female sex workers in Ukraine, reported that nonpermanent condom use was associated with variables such as lower age, alcohol consumption, having fewer customers, and lack of participation in HIV prevention programs. ${ }^{21}$ In a study done by Bandyopadhyay et al among 296 female sex workers in India, $37.5 \%$ did not use condoms continuously. Having a non-monetary partner, violence, and alcohol-related sex were reasons for not using condoms consistently. From the participants' point of view, the most important reason for not using condoms was trust in the partner. ${ }^{22}$ In a qualitative study conducted by Lotfi et al in Iran in 2013, Barriers to condom use among women at risk of HIV/AIDS, perceived lack of perceived threat, lack of motivation, inadequate knowledge, lack of control, and negative attitude toward condoms were the most common reasons not to use them. ${ }^{3}$ Another qualitative study done by Ghimire et al among female sex workers in Nepal showed that low self-efficacy, client rejection, poverty, powerlessness and fear of the police were the most important reasons for not using condoms among female sex workers. ${ }^{23}$

Since condom use is one of the most essential HIV/ AIDS prevention interventions, identifying the reasons for not using it, especially in female sex workers who are among the most vulnerable groups, can be very useful in future interventions in this area. Condom use has a complex and multidimensional nature that is influenced by various factors ${ }^{5,24,25}$ and these factors can be different in different societies and cultures. Therefore, it seems necessary to study this phenomenon in Iran which has its own cultural and social characteristics. Also, since most studies in this area are quantitative, ${ }^{22,26-28}$ a qualitative study of this phenomenon and looking at the barriers to condom use from the perspective and experience of female sex workers themselves can be useful. The qualitative approach was used to identify the barriers to condom use among female sex workers in Tehran, Iran.

\section{Materials and Methods}

In this study, according to the research topic, a proper approach to the subject, namely the qualitative approach and the conventional content analysis method, was used because it allows for greater understanding and realization of sensitive issues. ${ }^{29,30} \mathrm{~A}$ semi-structured qualitative approach to the study of phenomena is a useful way to study less known and culturally relevant phenomena and has great potential for exploring the symbolic meanings of social phenomena. ${ }^{31-33}$

The study population was made up of female sex workers in Tehran in 2018. Inclusion criteria were having a history of sex work, lack of continuous use of condoms in sexual relationships, being a resident of Tehran, and willingness to participate in the study. The sampling method was initially purposive in that the researchers selected two samples by referring to places where services were offered to female sex workers, and then the rest were selected through snowball sampling, being introduced by them. The sample was then asked to introduce the women who had an experience of being a sex worker to the researchers.

The instrument of data collecting in this study was a semi-structured interview so that the interviews were conducted individually and face-to-face, beginning with some general questions (Table 1) such as, "Do you want your partner to use a condom? If not, why?"; "Can condom use affect your relationship with your partner? Explain it."; "If you want to use condoms, can you provide it easily? Explain it."; "What makes you reluctant to use a condom?"; "Aren't you afraid of getting HIV if you do not use condoms?"; "What do you think about AIDS?" And then, in order to find out more deeply about the subject matter, other exploratory questions were asked according to the samples' answer. Each interview lasted 45 to 60 minutes on average. The time and place of the interviews were selected according to the samples' choices and conditions. Most interviews were conducted in places such as the sample home and public spaces such as parks.

The data analysis process began after the first interview, and we formulated the codes obtained in each interview as questions for subsequent interviews to see if the other participants had similar experiences to get more 
Table I Interview Questions

\begin{tabular}{|l|l|}
\hline Number & Questions \\
\hline 1 & Do you want your partner to use a condom? If not, why? \\
\hline 2 & $\begin{array}{l}\text { Can condom use affect your relationship with your } \\
\text { partner? Explain it }\end{array}$ \\
\hline 3 & $\begin{array}{l}\text { If you want to use condoms, can you provide it easily? } \\
\text { Explain it }\end{array}$ \\
\hline 4 & $\begin{array}{l}\text { What makes you reluctant to use a condom? } \\
\text { Are not you afraid of getting HIV if you do not use } \\
\text { condoms? }\end{array}$ \\
\hline 6 & \begin{tabular}{l} 
What do you think about AIDS? \\
Does the type of relationship you have with your \\
customers affect the use or non-use of condoms? \\
\hline 7
\end{tabular} \\
\hline
\end{tabular}

productive concepts. Data collection and analysis continued until the theoretical saturation was reached by interviewing 22 persons, with no new code being formed and all codes previously obtained and duplicated. To avoid false theoretical saturation, however, the researchers conducted another five interviews after repletion of codes in interview NO.17, to be more confident of achieving accurate theoretical saturation, with no new code being formed in the next five interviews. The researchers concluded that they would stop the data collection process because theoretical saturation has been obtained.

Graneheim and Lundman's method was used for data analysis. ${ }^{34}$ First, all interviews were transcribed on paper, then typed and stored in Word 2010. Then, in the second phase, the text of the interviews was read and reviewed by two members of the research team several times so that the researchers had sufficient knowledge of the data, and in the third stage the data were subdivided into meaning units (codes) in the form of sentences and paragraphs related to the original meaning. Since the interviews and topics were separated from each other, then each topic was divided into categories, so that the categories and sub-categories of each interview were identified and summarized. The codes were classified according to concept and meaning similarity. The process of data reduction continued across all units of analysis and sub-categories, eventually falling into the main categories that were more general and conceptual, and then themes were introduced.

In order to comply with ethical considerations, participants were informed about the purpose and necessity of the research before the interview and participated in the research with informed consent. Participants' written consent was gained to participate in the research and recording of their voices and permission to take quotes from their interviews. It should be noted that this study was conducted in accordance with the Helsinki Declaration. They were assured that the obtained information would only be used for research purposes and kept confidential during the publication of their research results so that they could be unidentifiable. They were also given the option to interrupt the interview process wherever they found it necessary, or postpone it to another time.

In order to ensure the validity and strength of the research, the criteria of Guba and Lincoln were considered. ${ }^{35}$ Credibility was achieved by reviewing the manuscripts by the participants and the long-term involvement of the researcher with the research field and the participants. Sampling was also attempted to maximize demographic variability to increase the validity of the data. Confirmability was established by maintaining the researchers' neutrality as well as reviewing the extracted codes and classes by two members of the research team and achieving an agreement. Dependability or consistency of findings were provided by typing and analyzing interviews as soon as possible, using expert colleagues' opinion in qualitative research and sex work, and re-reading the entire data. Transferability was also made possible through the provision of many direct quotes and rich data explanations.

\section{Results}

Totally, 22 female sex workers participated in the study, whose demographic characteristics are listed in Table 2. The data analysis process also resulted in the formation of 3 categories and 7 sub-categories (Table 3), followed by explanations and citations.

\section{Individual Factors}

This category consists of the sub-categories of not knowing HIV properly, opposition to loyalty and love, and personality traits.

\section{Not Knowing HIV Properly}

Many female sex workers did not have a proper understanding of HIV and its transmission and other sexually transmitted diseases. Hence it affected the use of condoms, and they did not see much need to use them.

"I don't accept everyone. Most of my clients are highborn and gentleman so I'm not worried about HIV and I don't need condoms" (Interviewee 6) 
Table 2 Demographic Information of Participants

\begin{tabular}{|c|c|c|}
\hline Variables & Dimension & $\mathbf{N}(\%)$ \\
\hline \multirow[t]{3}{*}{ Age } & $<25$ & 7 (3I.8I) \\
\hline & $25-40$ & $10(45.45)$ \\
\hline & $>40$ & $5(22.72)$ \\
\hline \multirow[t]{4}{*}{ Condom use } & Never & $4(18.18)$ \\
\hline & Very little & $10(45.45)$ \\
\hline & Low & $6(27.27)$ \\
\hline & Much & 2 (9.09) \\
\hline \multirow[t]{3}{*}{ Duration of sex worker } & $<5$ & $10(45.45)$ \\
\hline & $5-10$ & $8(36.36)$ \\
\hline & $>10$ & $4(18.18)$ \\
\hline \multirow[t]{3}{*}{ Number of relationships a week } & $1-3$ & $8(36.36)$ \\
\hline & $4-6$ & $9(40.90)$ \\
\hline & +6 & $5(22.72)$ \\
\hline \multirow[t]{2}{*}{ HIV infection } & Yes & $6(27.27)$ \\
\hline & No & $16(72.72)$ \\
\hline
\end{tabular}

"Someone who has HIV dies soon while I have had relationship with my clients for many years" (interviewee 9)

"HIV is more transmitted through anal sex, which I don't have, so I don't need to use condoms anymore" (interviewee 12)

"HIV is transmitted more from a woman to a man; if the man has HIV it cannot be hazardous to the woman" (Interviewee 11)

Therefore, female sex workers were not concerned about the transmission of HIV and did not feel the need to use condoms because of their wrong understandings and beliefs about HIV and its transmission ways.

\section{Opposition to Loyalty and Love}

Many female sex workers saw the use of condoms as a sign of distrust, disloyalty, and anti-love, so they used it less. In Iranian society, there is an opinion that condoms should not be used in sexual intercourse with someone close. The idea that causes not to use condoms by some female sex workers in their sexual affairs.

"When you want to use a condom in an intimate relationship, I think it means you don't like the guy" (interviewee 15)

"When I ask my emotional friends to use a condom, they definitely get upset and think that I have no feeling to them" (Interviewee 19)
Table 3 Categories, Sub-Categories and Codes

\begin{tabular}{|c|c|c|}
\hline Categories & $\begin{array}{l}\text { Sub- } \\
\text { Categories }\end{array}$ & Codes \\
\hline $\begin{array}{l}\text { Individual } \\
\text { factors }\end{array}$ & $\begin{array}{l}\text { Not knowing } \\
\text { HIVIAIDS } \\
\text { properly } \\
\text { Opposition to } \\
\text { loyalty and love } \\
\text { Personality } \\
\text { characteristics }\end{array}$ & $\begin{array}{l}\text { Lack of enough knowledge about } \\
\text { AIDS, optimism about clients } \\
\text { because my clients are highborn } \\
\text { so they do not have HIV, a stylish } \\
\text { client does not have HIV, HIV } \\
\text { patients die very soon } \\
\text { Using condoms is a sign of lack of } \\
\text { intimacy, not using a condom is } \\
\text { a sign of love and using it shows } \\
\text { distrust } \\
\text { Disappointed about future, be } \\
\text { risky in sex, Drug abuse, Fatalism }\end{array}$ \\
\hline $\begin{array}{l}\text { Structural } \\
\text { factors }\end{array}$ & $\begin{array}{l}\text { Partner's desire } \\
\text { Problems with } \\
\text { condom } \\
\text { availability }\end{array}$ & $\begin{array}{l}\text { Partner's violence, Partner's } \\
\text { consent, Fear of partner's bad } \\
\text { response } \\
\text { Condoms are expensive, scarcity } \\
\text { of condoms, limited access to } \\
\text { good condoms }\end{array}$ \\
\hline $\begin{array}{l}\text { Cultural } \\
\text { factors }\end{array}$ & $\begin{array}{l}\text { Cultural taboos } \\
\text { Following the } \\
\text { models }\end{array}$ & $\begin{array}{l}\text { Difficulty of talking about } \\
\text { condoms, feeling embarrassed to } \\
\text { get condoms, bad behavior of } \\
\text { pharmacies and drugstores staff } \\
\text { Lack of condom use in porn } \\
\text { videos, not being used among } \\
\text { friends, not being used in marriage } \\
\text { and romance }\end{array}$ \\
\hline
\end{tabular}

"Using condoms causes to ruin a relationship and no love exist between two partners." (Interviewee 17)

"My sex partner I have an emotional relationship with, and I like him, doesn't use a condom because he says that makes him enjoy less. So, I let him have sex without a condom" (Interviewee 16)

Since many female sex workers saw condom use as an expression of lack of interest and love, they did not see the need to use condoms in the emotional relationships they had with their few close friends. The amount of acquaintance and relationship they had with customers is competent in using or not using condoms, so most of the female sex workers have expressed that they rarely use condoms with customers who know them better or have an emotional relationship, comparing to the customers who come to them occasionally.

\section{Personality Characteristics}

Some of the personality characteristics of female sex workers cause them to have insecure intercourse. 
"I lost everything. It doesn't matter to me that I get HIV anymore. At the end, I will die sooner and get comfortable" (Interviewee 9)

"I know I sometimes have to use a condom, but I don't know why I get indifferent" (Interviewee 18)

"When I use crystal with my customers, neither they nor I understand anything. So, I don't use condoms much, I just think about it after sex" (Interviewee 4)

"I think if God wants you to get sick you will be sick and if God doesn't you won't, so I think using or not using condoms is not very important" (Interviewee 6)

Therefore, having some personality characteristics such as disappointment, risk-taking, drug abuse, and fatalism made women more likely to have an unsafe relationship and not to use condoms.

\section{Structural Factors}

This category consists of sub-categories of sexual Partner's desire and Problems with condom availability and refers to structures that prevent the use of condoms in female sex workers.

\section{Partner's Desire}

Since sex work is a crime in Iran, female sex workers are in a weak position so that even if they want to use a condom during sexual intercourse, if their sexual partner does not have such a desire, they will be forced to have insecure sex. In other cases, female sex workers also consent to sex without using a condom to gain more customer satisfaction for more money.

\footnotetext{
"Sometimes a customer promised to use a condom but he went back on his word in the middle of sex and I couldn't do anything because he threatened me" (Interviewee 11)

"Some customers paid more to let them not use condoms and I agreed". (Interviewee 9)

"Even though I know my boyfriend has relationships with many women, I am afraid to ask him to use condoms because I know he breaks up with me" (Interviewee 18)
}

\section{Problems with Condom Availability}

Many female sex workers complained about the high cost of condoms, their poor quality, their shortage, and availability in a limited number of pharmacies.
"The condom is too expensive for us and we wouldn't insist on using it if the customer didn't have it" (Interviewee 3)

"Only pharmacies supply condoms, even some do not have them, so you have to go a long way to get condoms in this busy Tehran" (Interviewee 2)

"The high-quality condoms are rare, and the available ones cost me a lot. A couple of times that I got low- quality ones, the customers threw them out because they were so useless" (Interviewee 14)

Thus, many female sex workers, despite their desire to use condoms in their relationships, do not use condoms because of the expensiveness and difficulty of access. In this way they endanger their health and their sexual partners' health. Another reason for the scarcity of condoms may be that in Iran, only pharmacies sell condoms, and because the use of condoms in Iran is minimal and has few buyers, most pharmacies prefer not to sell them.

\section{Cultural Factors}

This category consists of sub-categories of cultural taboos and Following the models and seems to be one of the most critical barriers to the use of condoms among female sex workers. These cultural barriers are mostly rooted in Iranian society's social and cultural structure, which forbidden talking about sexual behavior in public, which poses many challenges for condom use by a female sex workers.

\section{Cultural Taboos}

Many participants complained of severe cultural taboos that prevent talking about condoms and requesting them.

"Honestly, when I first started doing this, I didn't know what a condom was and its benefits. We had never talked about it at school and even in the family. So, I thought it was unnecessary" (Interviewee 17)

"Since they've never talked about condoms when you go somewhere and ask for you feel embarrassed. What is more, anyone who's there looks at you as you killed someone." (Interviewee 21)

"Sometimes when I go to the drugstore to get condoms people taunt me which bothers me." (Interviewee 8)

Therefore, since Iran is an Islamic country with a high sensitivity to sex issues, talking about sex is always a big taboo in the community that can make people's sexual 
socialization difficult so that it is difficult for many people to talk about condoms. Also, these limitations cause that in the society, especially female sex workers who belong to high-risk groups exposed to HIV, the awareness and understanding of the necessity of condoms use in high-risk sex did not form so that many of them do not use condoms in high-risk intercourses.

\section{Following the Models}

Many female sex workers considered a lack of condom use among friends or in pornographic films as a reason for not using them.

"Frankly, I don't use condoms when I see none of my friends who are female sex workers use condoms" (Interviewee 16)

"I never used a condom during ten years when I was married so I don't see it necessary now" (Interviewee 20)

"In the porn movies that they have sex more than twenty times a day, I rarely see they use condoms" (Interviewee 13)

Due to the lack of education and culture on condom use in Iran, condom use rate is low among female sex workers and even legal couples, so lack of condom use in sex has become a model.

\section{Discussion}

This qualitative study aimed to identify barriers to condom use among female sex workers in Tehran. Insufficient knowledge about HIV was one of the most important reasons for women not to use condoms, which is in line with research in this area ${ }^{36,37}$ Many female sex workers did not have a proper understanding of HIV and the ways of its transmission, and in many cases, they judged the appearance of people to realize having or not having HIV. Therefore, developing educational programs at the level of society is necessary to become more familiar with sexually transmitted diseases such as HIV.

Another barrier to using condoms was opposition to loyalty and love. Female sex workers and their clients perceived condom use as a kind of disinterest and lack of romance, so they did not use condoms in sex with sexual partners to whom they had feelings and interest. The type of relationship that female sex workers have with their clients affects their use or non-use of condoms. Most female sex workers said they did not use condoms during sex with regular customers or those who felt friendly with them, but were more likely to use condoms during sexual intercourse with first-time clients. Previous research has also suggested the use of condoms as opposition to love. ${ }^{38}$ In a 2013 study by Maher et al, having an emotional relationship with a sex partner was one of the reasons why condoms were not used by female sex workers. ${ }^{39}$

Another barrier to condom use was the personality characteristics of female sex workers. In the study of Lotfi et al, lack of motivation was one of the influencing personality characteristics of lack of condom use. ${ }^{3}$ The study of Bandyopadhyay et al 2018, Yoosefi Lebni et al 2019, and Yoosefi Lebni 2020 also refers to the relationship between drug use and having a high-risk sexual relationship. $^{22,40,41}$ This finding adds to previous research that not only environmental and social factors influence condom use, but also personality characteristics, such as disappointment about future, risk taking in sex, drug use and fatalism, influence it. Since sex work in Iran is considered an illegal activity, female sex workers are in poor conditions and do not receive any protection and support. These harmful conditions make them feel indifferent to their future and health. For this reason, they do not use condoms even in high-risk sex. Another influencing feature was fatalism. The Iranian society is religious, so they consider their health and illness to be in God's will and pay less attention to their actions, which is why some female sex workers did not believe in their preventive behavior.

Partner's desire was another reason for not using condoms: that is consistent with previous research in this area. $^{42-45}$ In another study conducted among female sex workers in Vietnam, the results showed that most customers were reluctant to use condoms and were even willing to pay more in exchange for unsafe sex. ${ }^{46}$ In fact, many of female sex workers stated that they were not able to resist the demands of their sexual partner and to obtain his consent and prevent violence they did not use condoms. As female sex workers in Iran are not socially and legally supported, they are in a weak position so that their clients can impose their desires on them.

Another reason came from problems of availability, which is consistent with some of the research done in this area. ${ }^{47,48}$ The McCool-Myers et al 2019 study also noted the low number of shops for providing condoms and their low diversity as reasons for not using them. ${ }^{49}$ This finding adds to previous research in this area. One of the most important ways to eliminate barriers of condom use is to facilitate access to condoms. In fact, since policies to 
increase population growth have been implemented in Iran in recent years, condom prices have risen noticeably, and condom sale is no longer current in the society, and some pharmacies even do not sell them. That is why access to condoms is limited.

Cultural taboos were another reason for not using condoms, which was one of the most critical and recent findings of this study that less discussed in previous studies. There are some misconceptions about condoms in Iranian society that in many cases condoms are only used by those who have high-risk sexual behavior. So, going to pharmacies to get condoms can lead to problems so that at first glance, they get the label of being a deviate. Also, since Islamic laws and norms are used in Iran, there is always a taboo to talk about sex and everything related to it. Even in educational settings, there is no education for condom use. That is why there is a kind of unknowingness.

Following the Models was one of the other barriers to condom use among female sex workers, which was one of the significant new results in this study that has not been addressed in previous research. In fact, since condom use is limited in Iranian society and most relationships go without it when female sex workers confront this, they somehow follow a model and are reluctant to use condoms. Many female sex workers also said that condoms were not used by many of their co-workers, as well as in the films that they watched, which could play a role in their behavior. Therefore, programs based on peer education are more necessary in this regard, because when most female sex workers use condoms, other colleagues also learn the behavior and use them in their sexual intercourse.

\section{Limitations}

Since sex work is considered a crime in Iran, identifying the samples was one of the most important limitations of this study, and the researchers solved this problem by choosing the appropriate sampling method (snowball sampling). Another limitation of this study was the fear of samples for participation in the research, which was removed by providing the research purpose and necessity of the research, and assuring them that their personal information would be kept confidential and not provided for any legal organization. Another limitation of the study was the willingness of some participants to interview with a female interviewer, which was overcome by using a female interviewer familiar with qualitative research.
Another limitation of this study was that it was performed only among female sex workers, but as the results showed, their clients were also really involved in lack of condom use, so it seems that other qualitative research studying clients of female sex workers can also help uncover the hidden aspects of the problem.

\section{Conclusion}

The results showed that lack of condom use was affected by individual, structural, and cultural factors. Therefore, an intervention program to increase condom use should be multilevel so that, at the individual level, it is necessary to educate female sex workers to raise their awareness of HIV, at the society level through education and preparation, taboos, and wrong cultural beliefs about condom use should be changed. Also, at the structural level, interventions should be included peer-based model, increase condom availability, promoting condom use, promoting Pre-exposure prophylaxis among sex workers as a possible means to prevent HIV.

\section{Ethics Approval and Informed Consent}

All procedures performed in studies involving human participants were in accordance with the ethical standards of the institutional and/or national research committee and with the 1964 Helsinki declaration and its later amendments or comparable ethical standards. This study was approved by the Research Council of Kermanshah University of Medical Sciences with the ethics code (IR. KUMS.REC. 1398.633). Participants were informed about the purpose and necessity of the research before the interview and written consent was obtained from all participants and included permission to take quotes from their interviews.

\section{Author Contributions}

All authors contributed to data analysis, drafting or revising the article, have agreed on the journal to which the article will be submitted, gave final approval of the version to be published, and agree to be accountable for all aspects of the work.

\section{Funding}

No funding was received for this work. 


\section{Disclosure}

The authors declare that they have no competing interests for this work.

\section{References}

1. Guiella G, Madise NJ. HIV/AIDS and sexual-risk behaviors among adolescents: factors influencing the use of condoms in Burkina Faso. Afr J Reprod Health. 2007;11(3):182. doi:10.2307/25549739

2. Fallahzadeh H, Morowatisharifabad M, Ehrampoosh M. HIV/AIDS epidemic features and trends in Iran, 1986-2006. AIDS Behav. 2009;13(2):297-302. doi:10.1007/s10461-008-9452-7

3. Lotfi R, Tehrani FR, Yaghmaei F, Hajizadeh E. Barriers to condom use among women at risk of HIV/AIDS: a qualitative study from Iran. BMC Women's Health. 2012;12(1):13. doi:10.1186/1472-6874$12-13$

4. Eilami O, Nazari A, Dousti M, Sayehmiri F, Ghasemi M. Investigation of HIV/AIDS prevalence and associated risk factors among female sex workers from 2010 to 2017: a meta-analysis study. HIV/AIDS. 2019;11:105.

5. Maenetje P, Lindan C, Makkan H, et al. HIV incidence and predictors of inconsistent condom use among adult men enrolled into an HIV vaccine preparedness study, Rustenburg, South Africa. PLoS One. 2019;14(4):e0214786. doi:10.1371/journal.pone.0214786

6. Shannon K, Strathdee SA, Goldenberg SM, et al. Global epidemiology of HIV among female sex workers: influence of structural determinants. Lancet. 2015;385(9962):55-71. doi:10.1016/S01406736(14)60931-4

7. Huang Y, Henderson GE, Pan S, Cohen MS. HIV/AIDS risk among brothel-based female sex workers in China: assessing the terms, content, and knowledge of sex work. Sex Transm Dis. 2004;31 (11):695-700. doi:10.1097/01.olq.0000143107.06988.ea

8. Reeves A, Steele S, Stuckler D, McKee M, Amato-Gauci A, Semenza JC. National sex work policy and HIV prevalence among sex workers: an ecological regression analysis of 27 European countries. Lancet HIV. 2017;4(3):e134e140. doi:10.1016/S23523018(16)30217-X

9. Prüss-Ustün A, Wolf J, Driscoll T, Degenhardt L, Neira M, Calleja JMG. HIV due to female sex work: regional and global estimates. PLoS One. 2013;8(5):e63476. doi:10.1371/journal. pone. 0063476

10. Baral S, Beyrer C, Muessig K, et al. Burden of HIV among female sex workers in low-income and middle-income countries: a systematic review and meta-analysis. Lancet Infect Dis. 2012;12 (7):538-549. doi:10.1016/S1473-3099(12)70066-X

11. Graham SM, Raboud J, McClelland RS, et al. Loss to follow-up as a competing risk in an observational study of HIV-1 incidence. PLoS One. 2013;8(3):e59480. doi:10.1371/journal.pone.0059480

12. Pettifor A, MacPhail C, Corneli A, et al. Continued high risk sexual behavior following diagnosis with acute HIV infection in South Africa and Malawi: implications for prevention. AIDS Behav. 2011;15(6):1243-1250. doi:10.1007/s10461-010-9839-0

13. Thurman T, Kidman R, Carton T, Chiroro P. Psychological and behavioral interventions to reduce HIV risk: evidence from a randomized control trial among orphaned and vulnerable adolescents in South Africa. AIDS Care. 2016;28(sup1):8-15. doi:10.1080/ 09540121.2016 .1146213

14. Levy E, Kaufman MR, Gidron Y, Deschepper R, Olley BO. Interventions targeting social cognitive determinants of condom use in the general Sub-Saharan population: a systematic review. Cogent Psychol. 2019;6(1):1637167. doi:10.1080/23311908.2019.1637167

15. Brüll P, Kessels LT, Repetto L, Dirkson A, Ruiter RA. ERPs reveal disengagement processes related to condom use embarrassment in intention-behavior inconsistent young adults. Arch Sex Behav. 2019;48(2):521-532. doi:10.1007/s10508-018-1217-4
16. Davis KC, Stappenbeck CA, Masters NT, George WH. Young women's experiences with coercive and noncoercive condom use resistance: examination of an understudied sexual risk behavior. Women's Health Issues. 2019;29(3):231-237. doi:10.1016/j. whi.2019.01.005

17. Rizkalla C, Bauman LJ, Avner JR. Structural impediments to condom access in a high HIV/STI-risk area. $J$ Environ Public Health. 2010;2010.

18. Wyatt GE. Enhancing cultural and contextual intervention strategies to reduce HIV/AIDS among African Americans. Am J Public Health. 2009;99(11):1941-1945. doi:10.2105/AJPH.2008.152181

19. Espada JP, Morales A, Guillén-Riquelme A, Ballester R, Orgilés M. Predicting condom use in adolescents: a test of three socio-cognitive models using a structural equation modeling approach. BMC Public Health. 2015;16(1):35. doi:10.1186/s12889-016-2702-0

20. Januraga PP, Mooney-Somers J, Gesesew HA, Ward PR. The logic of condom use in female sex workers in bali, Indonesia. Int J Environ Res Public Health. 2020;17(5):1627. doi:10.3390/ ijerph17051627

21. Iakunchykova OP, Burlaka V. Correlates of HIV and inconsistent condom use among female sex workers in Ukraine. AIDS Behav. 2017;21(8):2306-2315. doi:10.1007/s10461-016-1495-6

22. Bandyopadhyay K, Banerjee S, Goswami DN, Dasgupta A, Jana S. Predictors of inconsistent condom use among female sex workers: a community-based study in a red-light area of Kolkata, India. Indian $J$ Community Med. 2018;43(4):274.

23. Ghimire L, Smith WCS, van Teijlingen ER, Dahal R, Luitel NP. Reasons for non-use of condoms and self-efficacy among female sex workers: a qualitative study in Nepal. BMC Women's Health. 2011;11(1):42. doi:10.1186/1472-6874-11-42

24. Nattrass N. Poverty, sex and HIV. AIDS Behav. 2009;13(5):833-840. doi:10.1007/s10461-009-9563-9

25. Mallory C, Harris G, Stampley C. Midlife African-American women's protective and risky practices related to HIV. $J$ Adv Nurs. 2009;65(6):1248-1258. doi:10.1111/j.1365-2648.2009.04985.x

26. Asare M. Using the theory of planned behavior to determine the condom use behavior among college students. Am J Health Stud. 2015;30(1):43.

27. Kaneko N. Association between condom use and perceived barriers to and self-efficacy of safe sex among young women in Japan. Nurs Health Sci. 2007;9(4):284-289. doi:10.1111/j.14422018.2007.00338.x

28. George G, Maughan-Brown B, Beckett S, et al. Coital frequency and condom use in age-disparate partnerships involving women aged 15 to 24: evidence from a cross-sectional study in KwaZulu-Natal, South Africa. BMJ Open. 2019;9(3):e024362. doi:10.1136/bmjopen-2018024362

29. Maxwell JA. Designing a qualitative study. SAGE Handbook Appl Social Res Methods. 2008;2:214-253.

30. Irandoost SF, Taghdisi MH, Dehdari T, Bayangani B, Azadi NA. Obesity consequences from the people's perspective living in Kurdish regions of Iran: a qualitative content analysis. $J E d u c$ Health Promot. 2019;8.

31. Strauss A, Corbin J. Grounded theory methodology. Handbook Qual Res. 1994;17:273-285.

32. Bayangani B, Irandoost SF, Ahmadi S. Qualitative study of typology of lifestyles: study of youth in Mahabad City of Iranian Kurdistan. Int J Business Social Science. 2013;4:14.

33. Khosravi B, Xosravi T, Ziapour A, Fattahi E, Chaboksavar F, Yoosefi Lebni J. Challenges and problems facing 2017 kermanshah earthquake survivors: a qualitative study. Community Ment Health J. 2020. doi:10.1007/s10597-020-00652-1

34. Graneheim UH, Lundman B. Qualitative content analysis in nursing research: concepts, procedures and measures to achieve trustworthiness. Nurse Educ Today. 2004;24(2):105-112. doi:10.1016/j.nedt.2003.10.001 
35. Lincoln YS, Guba EG. Establishing trustworthiness. Naturalistic Inquiry. 1985;289:331.

36. Maticka-Tyndale E. Condoms in sub-Saharan Africa. Sex Health. 2012;9(1):59-72. doi:10.1071/SH11033

37. Saggurti N, Raj A, Mahapatra B, et al. Prevalence and correlates of non-disclosure of HIV serostatus to sex partners among HIV-infected female sex workers and HIV-infected male clients of female sex workers in India. AIDS Behav. 2013;17(1):399-406. doi:10.1007/ s10461-012-0263-5

38. Zhongdan C, Schilling RF, Shanbo W, Caiyan C, Wang Z, Jianguo S. The $100 \%$ condom use program: a demonstration in Wuhan, China Eval Program Plann. 2008;31(1):10-21. doi:10.1016/j. evalprogplan.2007.09.001

39. Maher L, Mooney-Somers J, Phlong P, et al. Condom negotiation across different relationship types by young women engaged in sex work in Phnom Penh, Cambodia. Glob Public Health. 2013;8 (3):270-283. doi:10.1080/17441692.2013.767930

40. Yoosefi Lebni J, Ziapour A, Qorbani M, et al. Explaining the causes of crystal addiction in Tehran: a qualitative approach. $J$ Public Health. 2019. doi:10.1007/s10389-019-01093-1

41. Yoosefi Lebni J, Ziapour A, Qorbani M, et al. The consequences of regular methamphetamine use in Tehran: qualitative content analysis. Subst Abuse Treat Prev Policy. 2020;15:1-10. doi:10.1186/s13011020-00277-3

42. Lang DL, Salazar LF, DiClemente RJ, Markosyan K. Gender based violence as a risk factor for HIV-associated risk behaviors among female sex workers in Armenia. AIDS Behav. 2013;17(2):551-558. doi:10.1007/s10461-012-0245-7
43. Winskell K, Obyerodhyambo O, Stephenson R. Making sense of condoms: social representations in young people's HIV-related narratives from six African countries. Soc Sci Med. 2011;72(6):953-961. doi:10.1016/j.socscimed.2011.01.014

44. Bucardo J, Semple SJ, Fraga-Vallejo M, Davila W, Patterson TL. A qualitative exploration of female sex work in Tijuana, Mexico. Arch Sex Behav. 2004;33(4):343-351. doi:10.1023/B: ASEB.0000028887.96873.f3

45. Goodman ML, Harrell MB, Gitari S, Keiser PH, Raimer-Goodman LA. Self-Efficacy mediates the association between partner trust and condom usage among females but not males in a Kenyan cohort of orphan and vulnerable youth. Afr $J$ Reprod Health. 2016;20 (2):94-103. doi:10.29063/ajrh2016/v20i2.10

46. Rosenthal D, Oanh TTK. Listening to female sex workers in Vietnam: influences on safe-sex practices with clients and partners. Sex Health. 2006;3(1):21-32. doi:10.1071/SH05040

47. Crosby R, Yarber WL, Sanders SA, Graham CA. Condom discomfort and associated problems with their use among university students. $J$ Am College Health. 2005;54(3):143-147. doi:10.3200/ JACH.54.3.143-148

48. Muñoz FA, Pollini RA, Zúñiga ML, et al. Condom access: associations with consistent condom use among female sex workers in two northern border cities of Mexico. AIDS Education Prevention. 2010;22(5):455-465. doi:10.1521/aeap.2010.22.5.455

49. McCool-Myers M, Myo A, Carter JA. Barriers to purchasing condoms in a high HIV/STI-Z2\#Risk Urban Area. J Community Health. 2019;1-8.
International Journal of Women's Health

\section{Publish your work in this journal}

The International Journal of Women's Health is an international, peerreviewed open-access journal publishing original research, reports, editorials, reviews and commentaries on all aspects of women's healthcare including gynecology, obstetrics, and breast cancer. The

\section{Dovepress}

manuscript management system is completely online and includes a very quick and fair peer-review system, which is all easy to use. Visit http://www.dovepress.com/testimonials.php to read real quotes from published authors. 